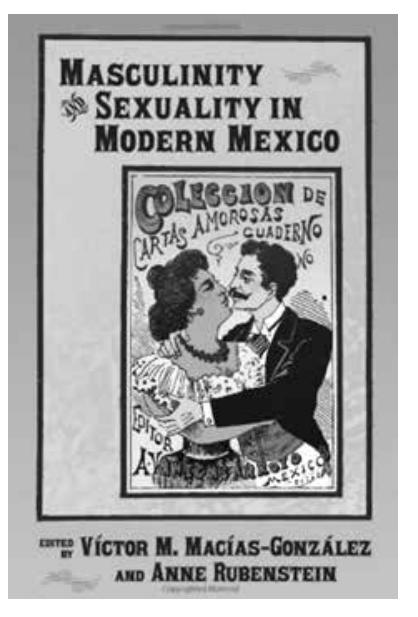

Masculinity and Sexuality in the History of Mexico

Maria Teresa Fernández Aceves Centro de Investigaciones y Estudios Superiores en Antropología Social-Occidente, Guadalajara, Jalisco, México materesafdez@gmail.com

Desacatos 50, enero-abril 2016, pp. 213-217
- Masculinity and Sexuality

in Modern Mexico

Víctor M. MAcías-GonzÁlez y AnNe

RUBENSTEIN (EDS.), 2012

University of New Mexico Press,

Albuquerque, $281 \mathrm{pp}$.

\section{La masculinidad y la sexualidad en la historia de México}

\author{
MARÍA TERESA FERNÁNDEZ ACEVES
}

M

asculinity and Sexuality in Modern Mexico es un libro colectivo sólido que contribuye de manera significativa al creciente campo de los estudios sobre masculinidad y sexualidad en México. ${ }^{1}$ Desde la historia cultural, de género y la antropología social, los nueve autores del libro analizan a fondo algunos estudios de caso sobre las construcciones de masculinidades y feminidades de 1880 a 2010, desde Oaxaca hasta Mexicali. El objetivo central de la obra es explicar el cambio de la relación entre el sexo biológico y el orden de género y cómo a lo largo del tiempo estas transformaciones generaron y reflejaron otro tipo de alteraciones políticas, sociales, culturales y espaciales. Los autores examinan a hombres, mujeres, gays, burócratas, estrellas de cine, músicos, intelectuales, viajeros, trabajadores y gente común y corriente en espacios públicos y privados. Recurren a la mirada crítica de la perspectiva de género y van más allá de las representaciones 
dualistas del orden de género para deconstruir las complejidades de ser hombre, ser mujer, la subjetividad masculina, las masculinidades exageradas, la masculinidad "transculturativa" — transculturative masculinities — , , la masculinidad débil de Agustín Lara que contrastaba con la feminidad fuerte e independiente con roles masculinizados de María Félix, y por último, la fluidez entre una virilidad exagerada de los charros-machos-cantantes con lo queer.

Lo novedoso de Masculinity and Sexuality in Modern Mexico es el vínculo de los estudios de masculinidad con el performance y los medios masivos de comunicación - Rubenstein, Pilcher, Wood, Mulholland-, las relaciones entre los individuos y las instituciones - Sloan, Garza, Schantz, Buffington- y la movilidad espacial como un sello de la modernidad -Macías-González, Schantz, Rubenstein-. Los textos se nutren de las discusiones teóricas sobre la perspectiva de género, lo queer, las identidades sociales y la teoría social. Los autores entretejen este aparato teórico con un abanico de fuentes primarias: autobiografías, novelas, ensayos, cartas, juicios criminales, prensa satírica, periódicos, películas, trabajo de campo y entrevistas.

La obra está dividida en dos partes, en las que se ilustran las experiencias y las representaciones en la construcción de masculinidades en relación con feminidades. Los nueve estudios de caso documentan que las masculinidades incluyen una amplia gama de conductas y arreglos. Las masculinidades historiadas surgieron por diferentes vías, ya fuera por negociar, quebrantar o subvertir el orden de género, para crear nuevas identidades de los sujetos.

Kathryn A. Sloan lo expone con claridad en su análisis de la constante negociación de los roles de género y la renegociación del contrato de hombres y mujeres en los raptos en Oaxaca a finales del siglo XIX. Su aportación más importante a los estudios de estupro y violación en México es el que se refiere a algunos casos en los que las mujeres asumieron papeles considerados más masculinos, persuadieron a sus amantes para que se fugaran y defendieron su honor ante los jueces. Explica que la masculinidad y la feminidad no funcionaban en polos binarios, sino que había espacios para que los sujetos ejercieran su agencia y transformaran su condición de vida.

Otro de los logros más importantes de esta obra es la vinculación que establece entre los espacios físicos con las estructuras sociales para escrudiñar las prácticas cotidianas de las masculinidades en baños públicos, cantinas, cafés, escuelas, clubes, fábricas, arenas deportivas, salas judiciales, balcones de cine, entre otros, y cómo éstas se moldearon por los aspectos espacial, social, cultural, racial, étnico y de clase social. En este sentido, sobresalen los capítulos de Víctor Macías-González, Eric Schantz y Anne Rubenstein.

Macías-González analiza escrupulosamente el uso de los baños públicos a finales del porfiriato en la ciudad de México y cómo éstos se convirtieron en sitios culturales que permitieron la propagación de nuevos discursos y prácticas culturales y de consumo, sobre el baño, la higiene, la limpieza, el ocio y la vestimenta. Reflexiona cómo el género y el espacio funcionaron en los baños públicos para moldear ciertas prácticas masculinas de acuerdo con la clase social, la etnicidad y la raza. El Estado porfirista, la elite y las clases medias negociaron nuevas ideas de una masculinidad "limpia" y occidentalizada, que contrastaba con la masculinidad "sucia" de los indígenas y la clase trabajadora. Como en toda política estatal que se pone en marcha, hay resultados y

2

Eric Schantz usa el término de masculinidad transculturativa para referirse a los turistas estadounidenses o sibaritas, como Valentino, que visitaban Mexicali por ser una ciudad muy abierta al comercio sexual y especializada en las "atracciones deportivas" masculinas. Para Schantz, "la reputación de zona roja" de Mexicali se basó en modelos mexicanos de privilegio masculino y ocio machista, pero muy influida por los modelos transnacionales de comercio de la industria del sexo (p. 102). 


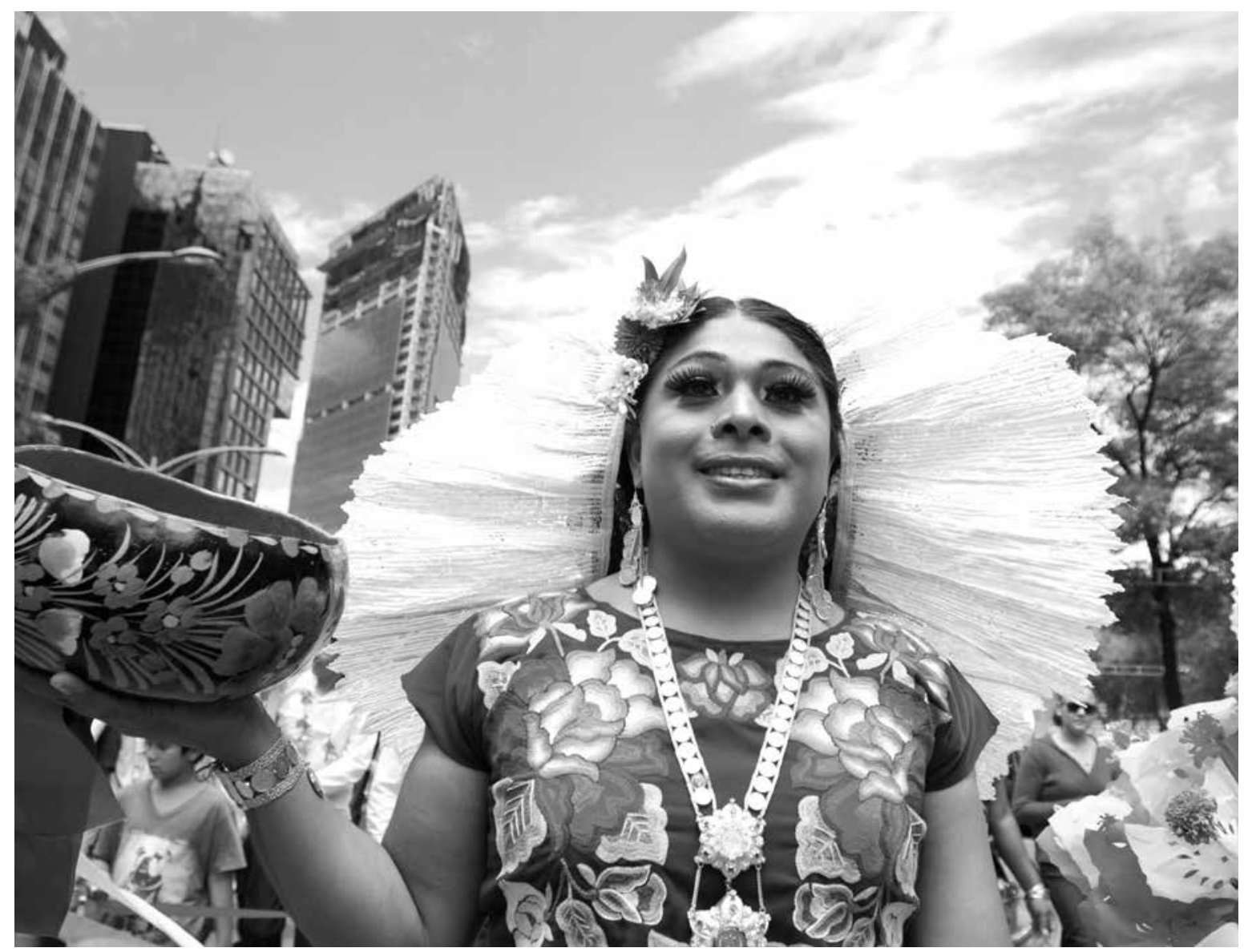

Octavio Hoyos Marcha del Orgullo Lésbico-Gay. Ciudad de México, 28 de junio de 2014

reacciones no planeados. Así sucedió con los baños públicos. El Estado y la elite querían limpiar al pueblo, pero en la práctica se abrió un espacio para la homosociabilidad y la libertad sexual. Esto provocó mucha ansiedad porque en los baños se infringía y se transgredía el orden de género heterosexual.

En contrapartida con el tema de los baños públicos y su homosociabilidad, que provocó muchas ansiedades en el porfiriato, Eric Schantz nos ofrece su acucioso estudio acerca del distrito de zona roja de Mexicali de 1908 a 1925, el cual se impulsó como lugar para saciar las fantasías de la masculinidad exagerada de estrellas de cine, turistas, empresarios y trabajadores migrantes. Para Schantz, éstas fueron masculinidades transculturativas que se mezclaron con el crecimiento de las industrias automovilística, de turismo y del ocio. La ubicación geográfica de Mexicali, vinculada a una de las regiones agrícolas más ricas de Estados Unidos, provocó un gran crecimiento del comercio sexual cerca del barrio chino, donde se privilegió la satisfacción de los deseos y el ocio masculinos en un entorno casi sin restricciones sexuales.

Con cierta semejanza a lo sucedido con la libertad masculina en Mexicali, en los cines, puntualiza Anne Rubenstein, a pesar de ser espacios públicos y privados, hubo cuantiosos casos de masculinidades que transgredían "lo propio" de ser un 
hombre: masculinidades muy agresivas y rebeldes desde el surgimiento del cine hasta la década de 1960. La variable de estas prácticas y los performances era la conformación de la audiencia, si era sólo masculina o si había mujeres presentes. Para controlar las prácticas masculinas desbordadas en los cines, se establecieron lineamientos que pretendían regular la conducta adecuada de los hombres.

La violencia verbal masculina en los cines, descrita por Rubenstein, es escudriñada por Robert Buffington en la prensa satírica - caricaturas y poemas-y en los juicios criminales de finales del porfiriato en la ciudad de México. Sostiene que la violencia masculina contra las mujeres, tan común a finales del siglo XIX, incluyó no sólo la brutalidad de los hombres de la clase trabajadora, sino que fue producto de una crisis de la subjetividad masculina más generalizada. La gran aportación de Buffington a los estudios de criminalidad es la deconstrucción de la violencia masculina y cómo los hombres se percibían a ellos mismos como hombres, es decir, su subjetividad. Así, argumenta que la diseminación de nociones modernas de organización social afectaron las condiciones de la subjetividad masculina, lo que generó la violencia contra las mujeres. Ésta funcionó de manera simbólica para contrarrestar el asalto de la modernidad en las subjetividades masculinas tradicionales. El ataque verbal y visual a las mujeres tenía la lógica cultural del sacrificio femenino para restablecer un orden de género y social tradicional.

En otro momento de la modernización del México del siglo xx y en la nacionalización del proceso posrevolucionario, Andrew Wood examina cómo el poeta y compositor Agustín Lara construyó su imagen de jarocho y romántico como parte de la cultura nacional. Lara mezcló lo romántico del México del siglo XIX con lo moderno del siglo XX. Creó una masculinidad débil, melancólica, sensible y de amante celoso que contrastó de manera significativa con las masculinidades de los charros rurales y del "pelado" de la ciudad de las películas mexicanas de los decenios de 1930 y 1940, discutidas brillantemente por Jeffrey Pilcher. Las masculinidades representadas por Jorge Negrete, el charro macho; Mario Moreno "Cantinflas", el "pelado", y Miguel de Molina, el gay, fueron confrontadas en una fuerte escisión sindical en 1946. Los dos primeros pugnaban por la autonomía sindical y el segundo se unió al sindicalismo autoritario de la Central de Trabajadores de México (CTM). El “pelado”-Cantiflas- confrontó públicamente al "marica” Molina por traicionar los derechos de los trabajadores y por respaldar la cooptación de la CTM de un sector de los trabajadores de la industria del cine. Pilcher sostiene que después de este enfrentamiento sindical en 1946, se transformaron las actuaciones de los personajes masculinos. En las películas mexicanas se dejaron atrás los papeles que cruzaban los roles masculinos y se acentuó una masculinidad que no coqueteaba con los hombres.

A pesar de este giro cinematográfico en las personificaciones de las masculinidades, Mary-Lee Mulholland sostiene que en la performatividad de la música ranchera y los mariachis, en particular en el caso de Vicente y Alejandro Fernández, visibilizan la ambivalencia de los roles de género y de la sexualidad entre el padre y el hijo. Para Mulholland, en la performatividad de estos cantantes hay un deslizamiento de lo macho a lo gay y se regresa a roles tradicionales de machos, mujeriegos y sensibles. Sostiene que esto refleja la complejidad y la ambigüedad de las sexualidades masculinas en Guadalajara y en México en general.

Recomiendo este libro colectivo para los especialistas en el México moderno, los estudios de género, de masculinidades y de sexualidad. Es una obra muy cuidada, con análisis matizados que contribuyen a entender las cambiantes construcciones sociales masculinas y femeninas de México desde finales del siglo XIX hasta principios del XX. Considero que sería de gran utilidad su traducción al español para fortalecer estos campos crecientes e innovadores en las ciencias sociales y humanidades. D 


\section{Bibliografía}

Cruz López Moya, Martín de la, 2010, Hacerse hombres cabales. Masculinidad entre tojolabales, Centro de Investigaciones y Estudios Superiores en Antropología Social/Universidad de Ciencias y Artes de Chiapas, México.

Laguarda, Rodrigo, 2010, Ser gay en la ciudad de México. Lucha de representaciones y apropiación de una identidad, 1968-1982, Centro de Investigaciones y Estudios Superiores en Antropología Social/Instituto Mora, México.

Ramírez Rodríguez, Juan Carlos y José Carlos Cervantes Ríos (coords.), 2013, Los hombres en México: veredas recorridas y por andar, Universidad de Guadalajara-Centro Universitario de Ciencias Económicas y Administrativas/Academia Mexicana de Estudios de Género de los Hombres, Zapopan. 